\title{
Application of biochar from crop residues for the removal of lead and copper
}

José M. De la Rosa ${ }^{1}$, Águeda Sánchez-Martín ${ }^{1}$, María L. Sánchez-Martín ${ }^{1}$, Nikolas Hagemannn ${ }^{2,3}$, Heike Knicker ${ }^{1}$, and Paloma Campos ${ }^{1^{*}}$

(1) Instituto de Recursos Naturales y Agrobiología de Sevilla (IRNAS-CSIC), Reina Mercedes 10, 41012, Seville, Spain, (2) Agroscope Zurich, Reckenholzstr. 191, Zurich, Switzerland, (3) Ithaka Institute, Arbaz, Switzerland. *pcampos@irnas.csic.es

\section{INTRODUCTION}

Due to the chemical composition and surface properties of biochar, a C-rich porous material produced by pyrolysis of biomass, it can act as ements [1,2] However its capacity to sorb these contamin wace elements $[1,2]$. However, its capacity to sorb these contaminants in a solution vales considerably depend on pyrolysis conditions, but also$$
\checkmark
$$

\section{Objective: to evaluat}

\section{MATERIALS AND METHODS}
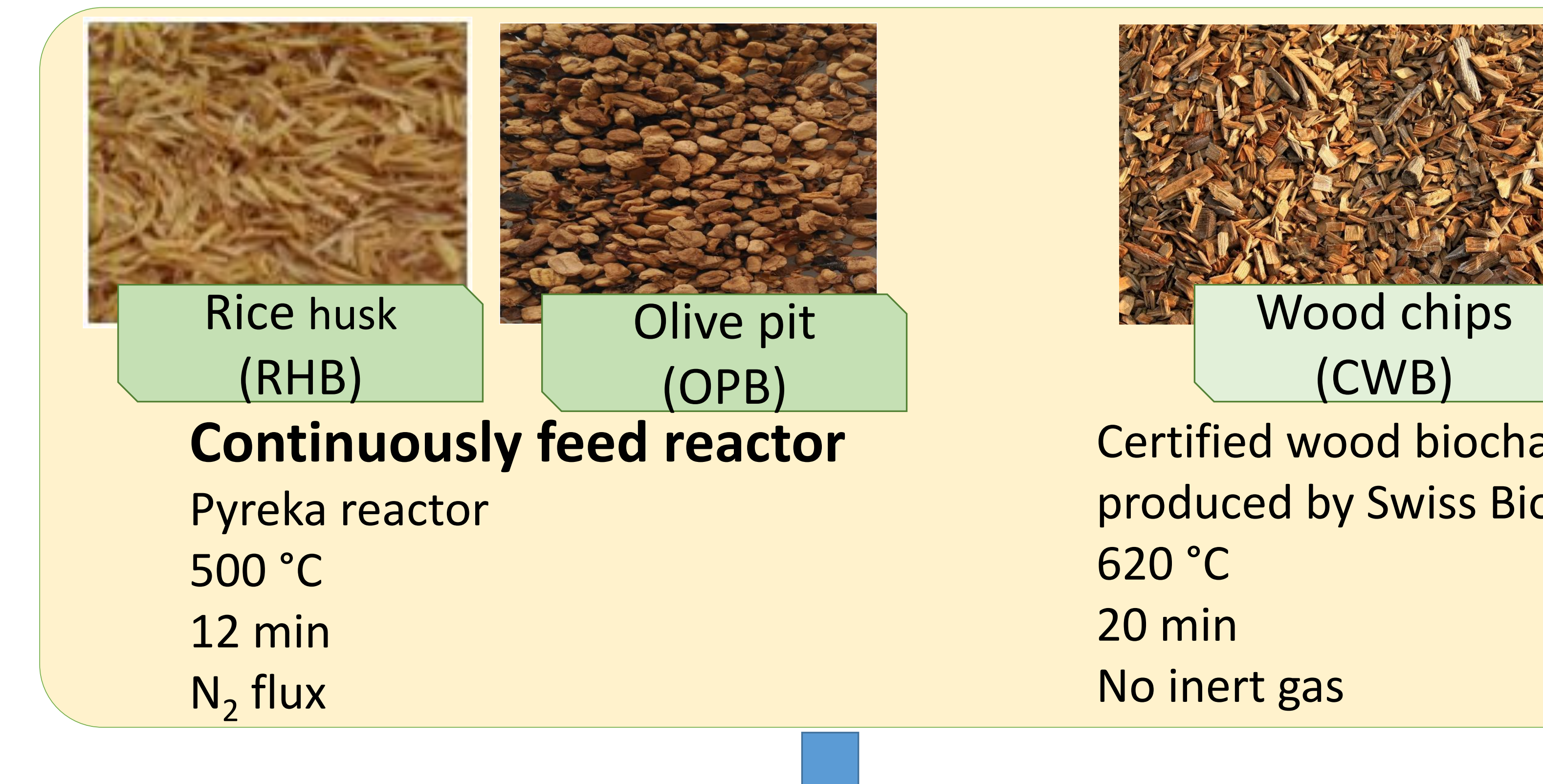
Certified wood biochar produced by Swiss Biochar $620^{\circ} \mathrm{C}$ 20 min

1. Biochar characterization

\section{- Elemental composition}

pH, Water Holding Capacity (WHC)

SSA-BET, iodine number, total acid and basid sites

$\mathrm{FT}-\mathrm{IR},{ }^{13} \mathrm{C}-\mathrm{NMR}$

\section{Batch adsorption experiments} Initial conc. $\mathrm{Cu}^{2+} / \mathrm{Pb}^{2+}$.

$0.05,0.1,0.5$

1,2 and $5 \mathrm{mM}$

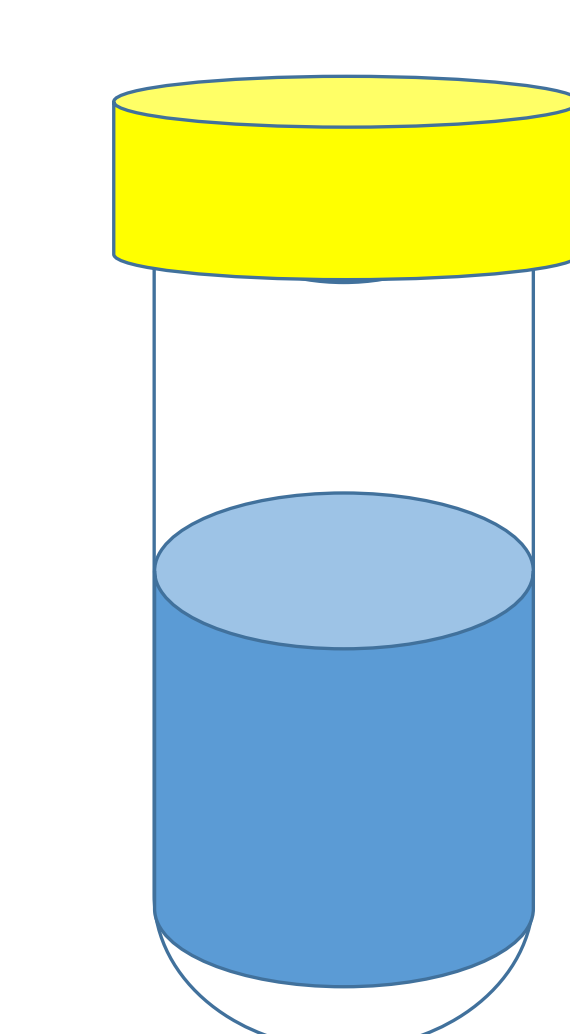

$20 \mathrm{mg} \quad \because \quad$ filtration $(0.45 \mu \mathrm{m})$

\section{RESULTS}

Table 1. Elemental analysis and ash content (\%) of biochars.

$$
\begin{array}{lcccccccccc} 
& \text { TC (\%) } & \text { TH (\%) } & \text { TN (\%) } & \mathrm{O}(\%) & H / \mathrm{C}_{\text {at }} & \mathrm{O} / \mathrm{C}_{\text {at }} & \mathrm{C} / \mathrm{N} & \multicolumn{3}{c}{\begin{array}{c}
\text { Ash content } \\
(\%)
\end{array}} \\
\hline \text { CWB } & 75.7 \pm 0.3 & 1.80 \pm 0.02 & 0.30 \pm 0.06 & 18.7 & 0.3 & 0.19 & 252 & 3.5 & \pm & 0.7 \\
\text { RHB } & 53.7 \pm 0.1 & 1.61 \pm 0.02 & 0.51 \pm 0.24 & 9.48 & 0.4 & 0.13 & 106 & 34.7 & \pm & 0.5
\end{array}
$$

\begin{tabular}{|c|c|c|c|c|c|c|}
\hline & $\mathrm{pH}$ & WHC (\%) & $\begin{array}{c}\text { SSA-BET }\left(\mathrm{CO}_{2}\right. \\
\left.\mathrm{m}^{2} \mathrm{~g}^{-1}\right)\end{array}$ & $\begin{array}{l}\text { Iodine } \\
\text { Index }\end{array}$ & $\begin{array}{l}\text { Total basicity } \\
\left(\text { meq g }^{-1}\right)\end{array}$ & $\begin{array}{l}\text { Total acidity } \\
\left(\text { meq g }^{-1}\right)\end{array}$ \\
\hline & $9.95 \pm 0.18$ & \pm 39 & 403 & 149 & 0.95 & 1.69 \\
\hline RHB & $10.10 \pm 0.01$ & $595 \pm 22$ & 292 & 180 & 0.51 & 1.70 \\
\hline OPB & $9.34 \pm 0.09$ & $70 \pm 13$ & 473 & 123 & 0.05 & 0.17 \\
\hline
\end{tabular}

$\begin{array}{lllllllllll}\text { OPB } & 92.7 \pm 0.2 & 2.52 \pm 0.06 & 0.16 \pm 0.09 & 3.58 & 0.3 & 0.03 & 585 & 1.0 & \pm & 0.3\end{array}$

Table 2. Physical and chemical characteristics and Surface properties of biochars.

\section{a)}

\% Removal of $\mathrm{Cu}^{2+}$ by biochars

120

100

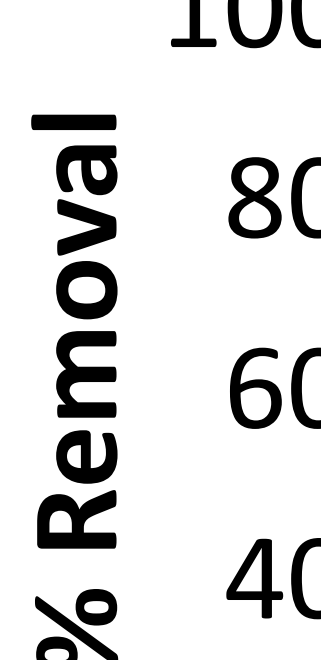

80

80
60
40

20

00

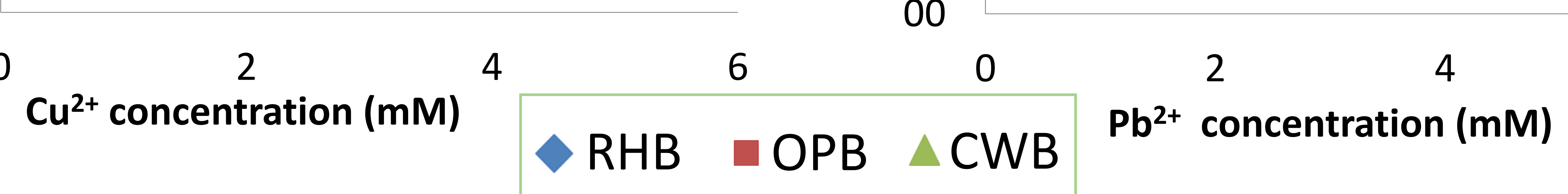

c) Capacity of adsorbents

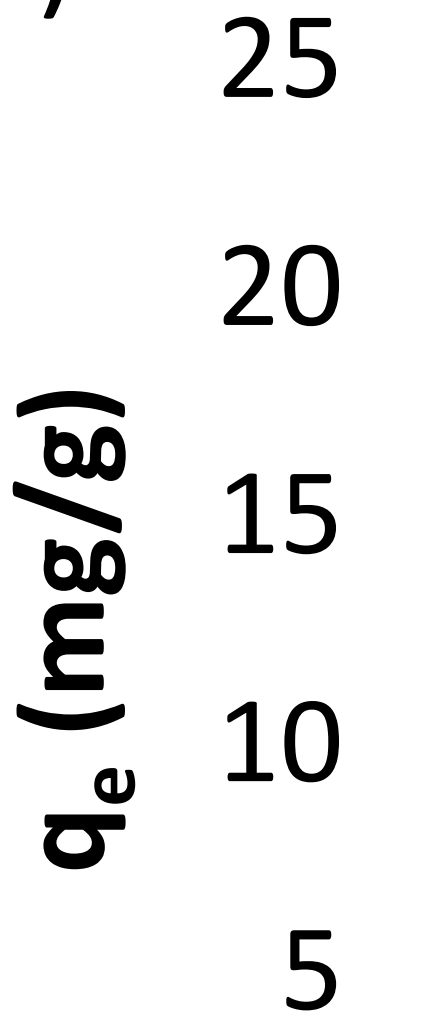

$20 \mathrm{~mL} 48 \mathrm{~h}, 25 \mathrm{rpm}$ Supernatant

Biochar $\because \because \frac{\text { Centrifugation \& }}{\longrightarrow}$ ICP-OES d) 120 Capacity of adsorbents

b) Removal of $\mathrm{Pb}^{2+}$ by biochars $100 \ldots 4$

गे 80

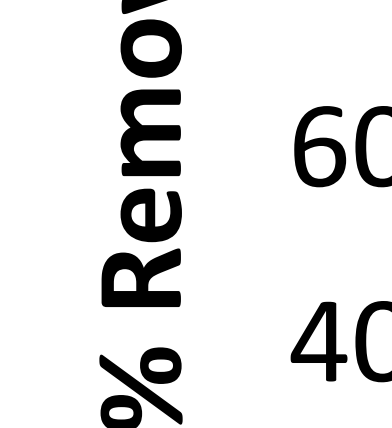

20

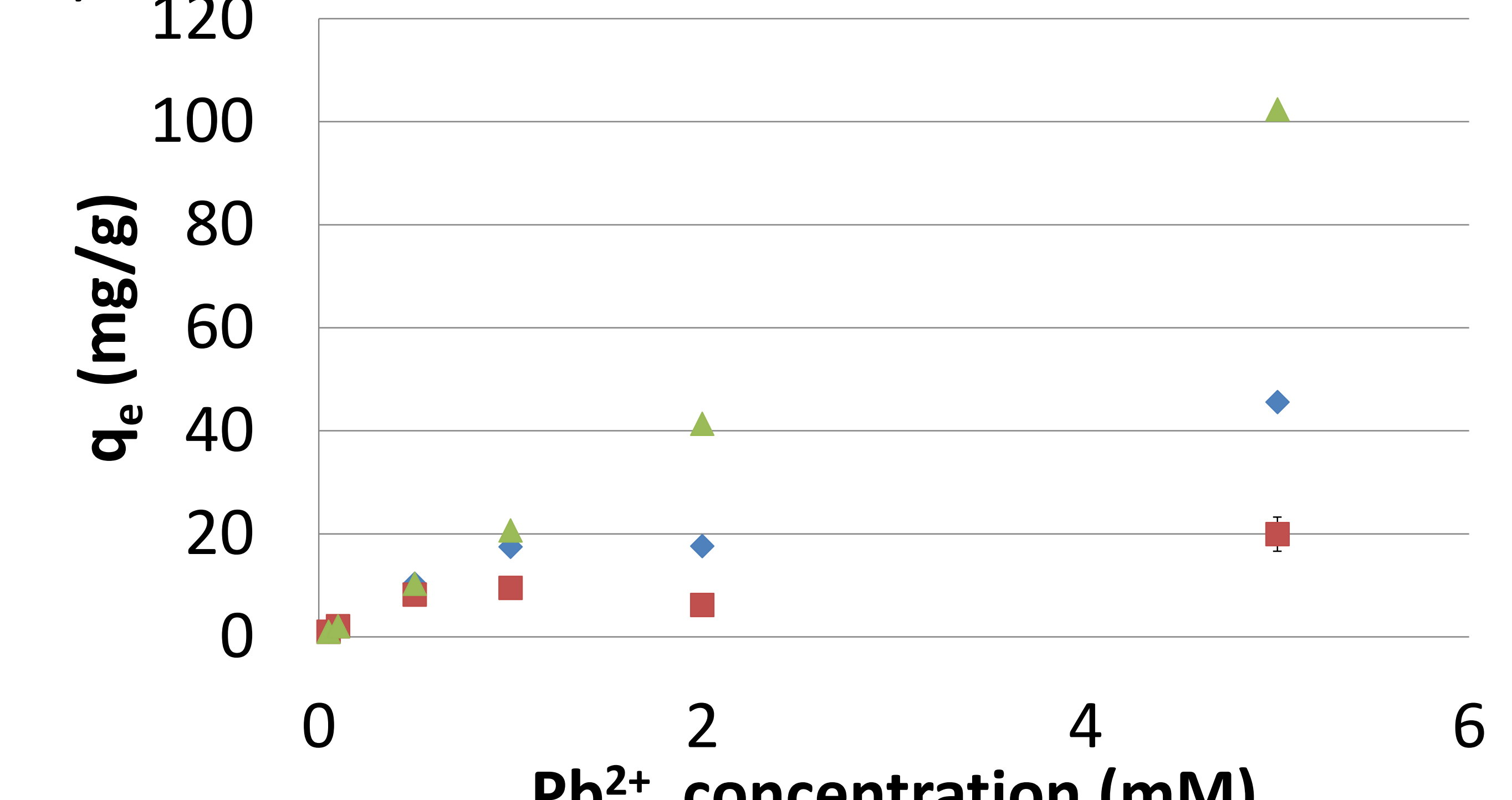

$\mathrm{Pb}^{2+}$ concentration (mM)

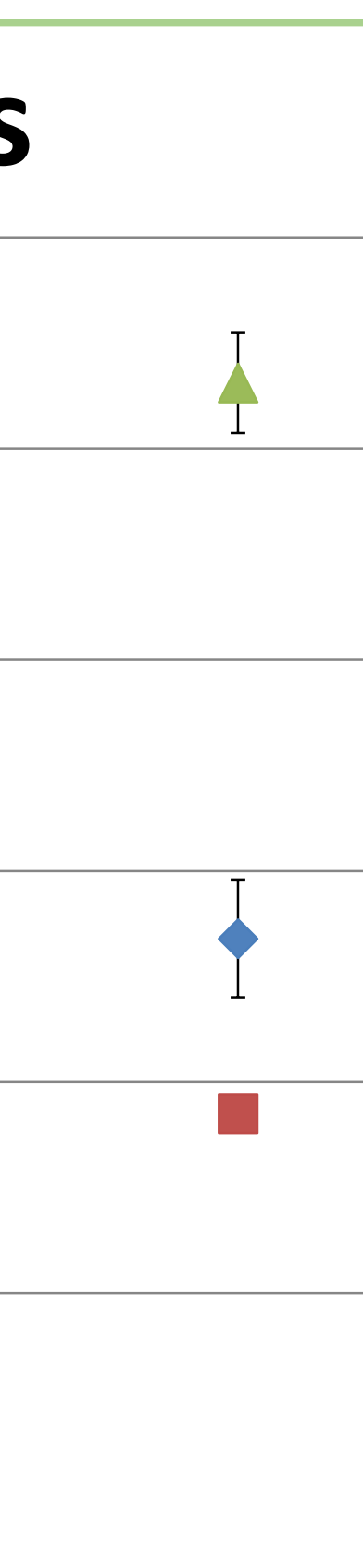

- TC $>50 \%$ for all biochars. Biochars showed high aromaticity.

- Greater SSA-BET measured with $\mathrm{CO}_{2}$ for OPB and CWB than RHB

- Greater basic and acid sites for RHB and CWB than OPB.

- \% Removal of the studied cations in the following order: $C W B>R H B>O P B$.

- Langmuir isotherm fitted well for RHB and CWB for both cations.

- Temkin and Freundlich fitted $\mathrm{Cu}^{2+}$ and $\mathrm{Pb}^{2+}$ adsorption for OPB, respectively.

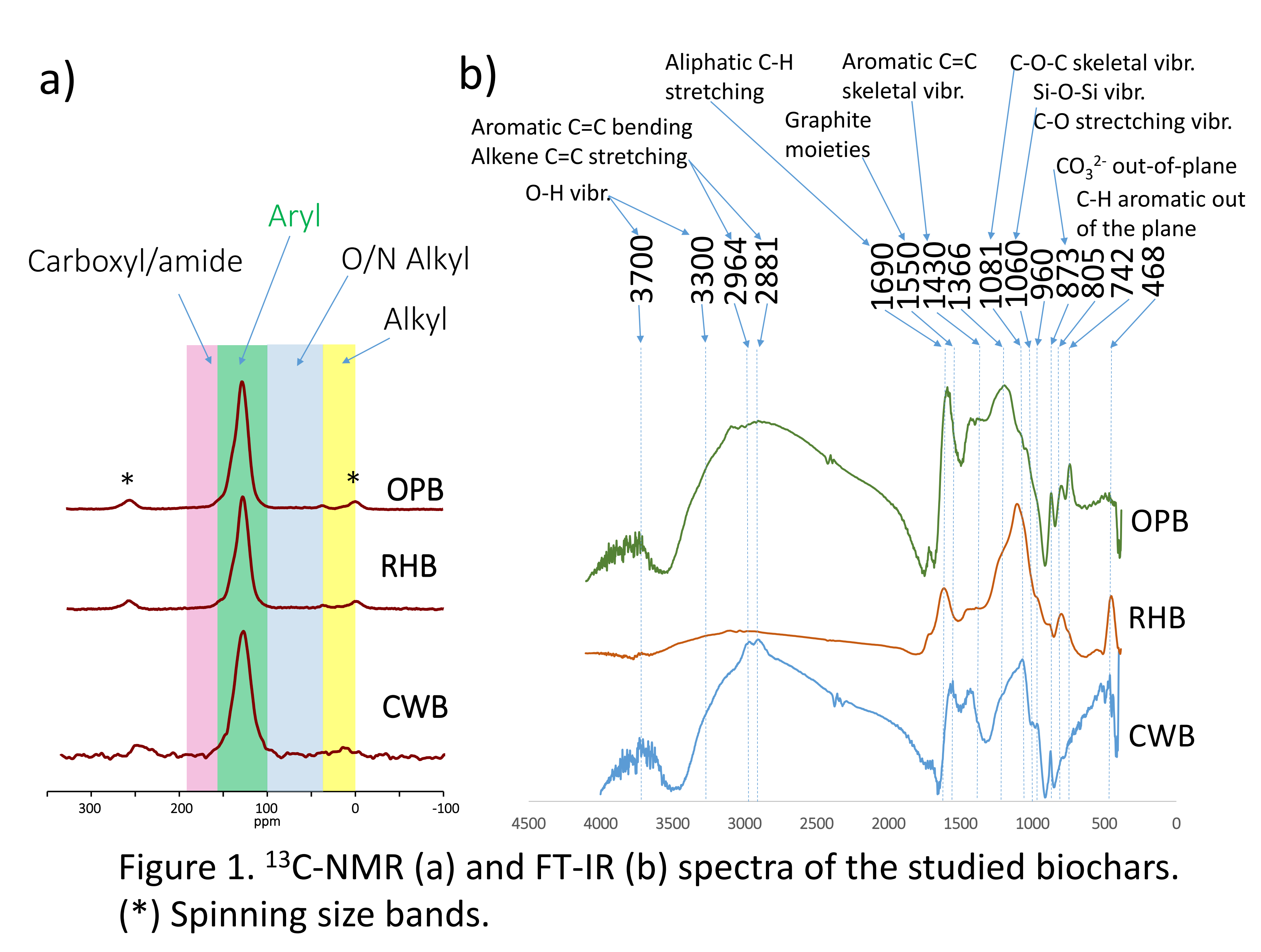

\section{CONCLUSIONS}

- High SSA-BET was not related with high adsorption capacity of the biochars. It may be more related to the total acidity.

CWB, followed by RHB, showed the greatest capacity for adsorption of $\mathrm{Cu}^{2+}$ and $\mathrm{Pb}^{2+}$ - OPB showed the greatest SSA-BET, whereas it also showed the lowest \% of removal for both cations. OPB showed few acid sites (only $0.17 \mathrm{meq}^{-1}$ ), related with low oxygen content and very low $\mathrm{O} / \mathrm{C}_{\text {at }}$ ratio.

- Langmuir model well fitted data of RHB and CWB, whereas Freundlich and Temkin fitted better adsorption data in OPB. 